\title{
Sinus Node Dysfunction due to Occlusion of the Sinus Node Artery during Percutaneous Coronary Intervention
}

\author{
Ofir Koren (D), 1,2 Dante Antonelli, ${ }^{1}$ Ranya Khamaise, ${ }^{3}$ Scott Ehrenberg, ${ }^{2}$ Ehud Rozner, ${ }^{1}$ \\ and Yoav Turgeman ${ }^{1,2}$ \\ ${ }^{1}$ Heart Institute, Emek Medical Center, Afula, Israel \\ ${ }^{2}$ Bruce Rappaport Faculty of Medicine, Technion Israel Institute of Technology, Haifa, Israel \\ ${ }^{3}$ Internal Medicine B, Emek Medical Center, Afula, Israel \\ Correspondence should be addressed to Ofir Koren; drkorenofir@gmail.com
}

Received 26 August 2020; Revised 8 February 2021; Accepted 19 March 2021; Published 30 March 2021

Academic Editor: Salvatore De Rosa

Copyright (c) 2021 Ofir Koren et al. This is an open access article distributed under the Creative Commons Attribution License, which permits unrestricted use, distribution, and reproduction in any medium, provided the original work is properly cited.

Background. Sinus node artery occlusion (SNO) is a rare complication of percutaneous coronary intervention (PCI). We analyze both the short- and long-term consequences of SNO. Methods. We retrospectively reviewed 1379 consecutive PCI's involving RCA and Cx arteries performed in our heart institute from 2016 to 2019. Median follow-up was $44 \pm 5$ months. Results. Among the 4844 PCIs performed during the study period, 284 involved the RCA and the circumflex's proximal segment. Periprocedural SNO was estimated by angiography observed in 15 patients (5.3\%), all originated from RCA. The majority of SNO occurred during urgent and primary PCIs following acute coronary syndrome (ACS). Sinus node dysfunction (SND) appeared in $12(80 \%)$ of patients. Four (26.6\%) patients had sinus bradycardia, which resolved spontaneously, and 8 (53.3\%) patients had sinus arrest with an escaped nodal rhythm, which mostly responded to medical treatment during the first 24 hours. There was no association between PCI technique and outcome. Three patients (20\%) required urgent temporary ventricular pacing. One patient had permanent pacemaker implantation. Pacemaker interrogation during follow-up revealed a recovery of the sinus node function after one month. Conclusion. SNO is rare and seen mostly during angioplasty to the proximal segment of the RCA during ACS. The risk of developing sinus node dysfunction following SNO is high. SND usually appears during the first $24 \mathrm{~h}$ of PCI. The majority of SND patients responded to medical treatment, and only in rare cases were permanent pacemakers required.

\section{Introduction}

Sinus node supply by the sinus node artery (SNA) originates from RCA in almost $60 \%$ of cases and the circumflex artery in $30-40 \%$ [1]. In about $10-11 \%$ of cases, the sinus node has a dual blood supply by RCA and circumflex arteries [1].

Side branch occlusion of coronary arteries is a well-known complication of PCI (percutaneous coronary intervention), especially after stent deployment [2-6]. Previous reports describe iatrogenic occlusion of the sinus node artery in cases of proximal RCA (right coronary artery) and circumflex artery (Cx) intervention $[7-11]$.
Several case reports and small clinical trials described the short-term consequences of sinus node artery occlusion [12-15]. Therapeutic approaches and long-term outcomes are still unclear.

1.1. Study Rationale. The study aims are to analyze SNO incidence during PCI on the RCA and circumflex artery proximal segments, patients' clinical characteristics, and immediate and late outcome of SND as reported.

\section{Methods}

We conducted an observational cohort study in Emek Medical Center, a general, 500-bed teaching hospital in 
Israel's northeast region, belonging to the Clalit Health Services. We collected data from patients who underwent PCI from June 2016 to June 2019 who met the study inclusion criteria (Table 1).

Patients with evidence of sinus node dysfunction before the PCI, such as inappropriate sinus bradycardia, bradycardia-tachycardia syndrome, sinus pause or arrest, and sinoatrial (SA) exit block, were not included in the study. Patients with supraventricular arrhythmias (atrial tachycardia, atrial flutter, or atrial fibrillation), a cardiac implantable electronic device (CIED), and patients who needed coronary artery bypass graft surgery were also not included in the study.

We used computer-based data mining to identify coronary angiography involving the right coronary artery and circumflex artery proximal segments. Three senior cardiologists analyzed consecutive PCIs to determine SNO by angiography. Independent authors reviewed all personal medical records, ECG strips, and catheterization reports for documented sinus node dysfunction (Figure 1).

Emek Medical Center is a regional hospital that belongs to Clalit Health Services. We used a computerized scan of the hospital and Clalit Health Services databases for long-term follow-up. When there was not sufficient information regarding outcomes, an experienced physician reviewed the medical files and, if required, contacted the patient.

2.1. Ethics. The Emek Medical Center Ethics Committee approved the study following the Helsinki Convention. The IRB waived the informed consent due to patient data confidentiality and the study's methodology (No. EMC-113-19).

2.2. Sample Size. The sample size was calculated based on a previously reported SNO incidence of approximately $25 \%$ of PCI involving RCA and Cx's proximal segment. To achieve a confidence level of $95 \%$, a margin of error of $5 \%$, and a response distribution of $50 \%$, we required a minimum sampling size of 102 PCIs. Preliminary analysis revealed a lower than expected SNO incidence, which required us to increase the sample size.

2.3. Statistics. We described categorical variables using frequencies and percentages and continuous variables using mean \pm standard deviation. We used the T-test (or alternative Wilcoxon two-sample test) for continuous variables and multivariable models and one-way ANOVA to estimate SND appearance. A $P$ value $<0.05$ and CI 95\% were considered significant. SAS 9.4 software was used for statistical analysis.

\section{Results}

We performed 4844 PCIs during the study period. 15\% (284) of all RCA and circumflex artery interventions involved the proximal segment (186 and 98 for RCA and Cx arteries, respectively). The sinus node artery was originated from the proximal segment of the RCA in 181 (67\%) cases and the proximal segment of the circumflex artery in 68 (24\%) PCIs.

Sinus node artery occlusion was observed in 15 (5.3\%) patients and only during angioplasty to the RCA's proximal segment. None of the cases of SNO involved the circumflex artery. Patients' average age was $69.58 \pm 8.85$ years, and $86 \%$ of them were male. More than half of them were smokers who had hypertension, hyperlipidemia, and diabetes mellitus $(0.6,0.73,1.0$, and 0.53 , respectively). SNO was observed during primary and urgent PCI in almost $90 \%$ of cases (0.6 and 0.27 for immediate and urgent PCI, respectively) and mostly during inferior ST-elevation myocardial infarction and acute coronary syndrome (Table 2).

Sinus node dysfunction (SND) following SNO appears in $12(80 \%)$ of patients. Fours patients $(26.6 \%)$ had transient sinus bradycardia, which lasted for an average of 6.5 minutes (range of 2-12 minutes) and resolved spontaneously or after a vigorous cough. Eight patients (53.3\%) had sinus arrest with escaped nodal rhythm and mostly responded to medical treatment (1-2 mg of intravenous adrenaline or atropine). In three symptomatic patients, the escaped rhythm was consistent and followed by early hypoperfusion symptoms and signs and required temporary ventricular pacing. In two cases, the sinus node recovered during a 24-hour follow-up (Table 3). Persistent SNA occlusion followed by progressive hemodynamically instability was reported in one patient, which required a dual chamber permanent pacemaker (Figure 2).

We interrogate the pacemaker twice during a six-month follow-up (after 1 and 6 months from implantation). In the second interrogation, we observe the appearance of the sinus node.

During a median follow-up of $44 \pm 5$ months, none of the 14 patients who had sinus node occlusion developed sinus node dysfunction. Two patients underwent PCI during the follow-up period in LAD and Cx territories. Angiography of the PCIs revealed patent SNA.

\section{Discussion}

Our study indicates that sinus node artery occlusion during angioplasty involving the RCA's proximal segment and the circumflex artery is rare and occurs in about 5.3\% of all PCIs. This incidence is significantly lower than previously reported [5-7]. We believe that the methodology nature of the study could partially explain the low incidence. Previous studies identified sinus node dysfunction in a retrospective fashion. In our study, we reviewed prospectively all PCIs involving the proximal segment to find SNO cases.

The occlusion of the side branch is not necessitating sinus node dysfunction. Still, it has a high potential for developing SND and, in our study, $80 \%$ of all SNO cases resulted in some type of SND, which was higher than previously reported. We assume that the significant difference was related to the definition of sinus node dysfunction. In our study, we included all sinus node arrhythmias and, in particular, sinus bradycardia. Since most PCIs in our study involved the inferior wall's infarction, we assume that some 
TABLE 1: Inclusion and exclusion criteria.

Inclusion criteria Exclusion criteria

Evidence of sinus node dysfunction before PCI as follows:

1. Inappropriate sinus bradycardia

2. Bradycardia-tachycardia syndrome

3. Sinus pause or arrest

Coronary catheterization during the study period, including elective, urgent,

4. Sinoatrial (SA) exit block and STEMI PCIs

5. Known atrial tachycardia, atrial flutter, or atrial

fibrillation before PCI

6. Pacemaker, ICD, and CRT/P implantation

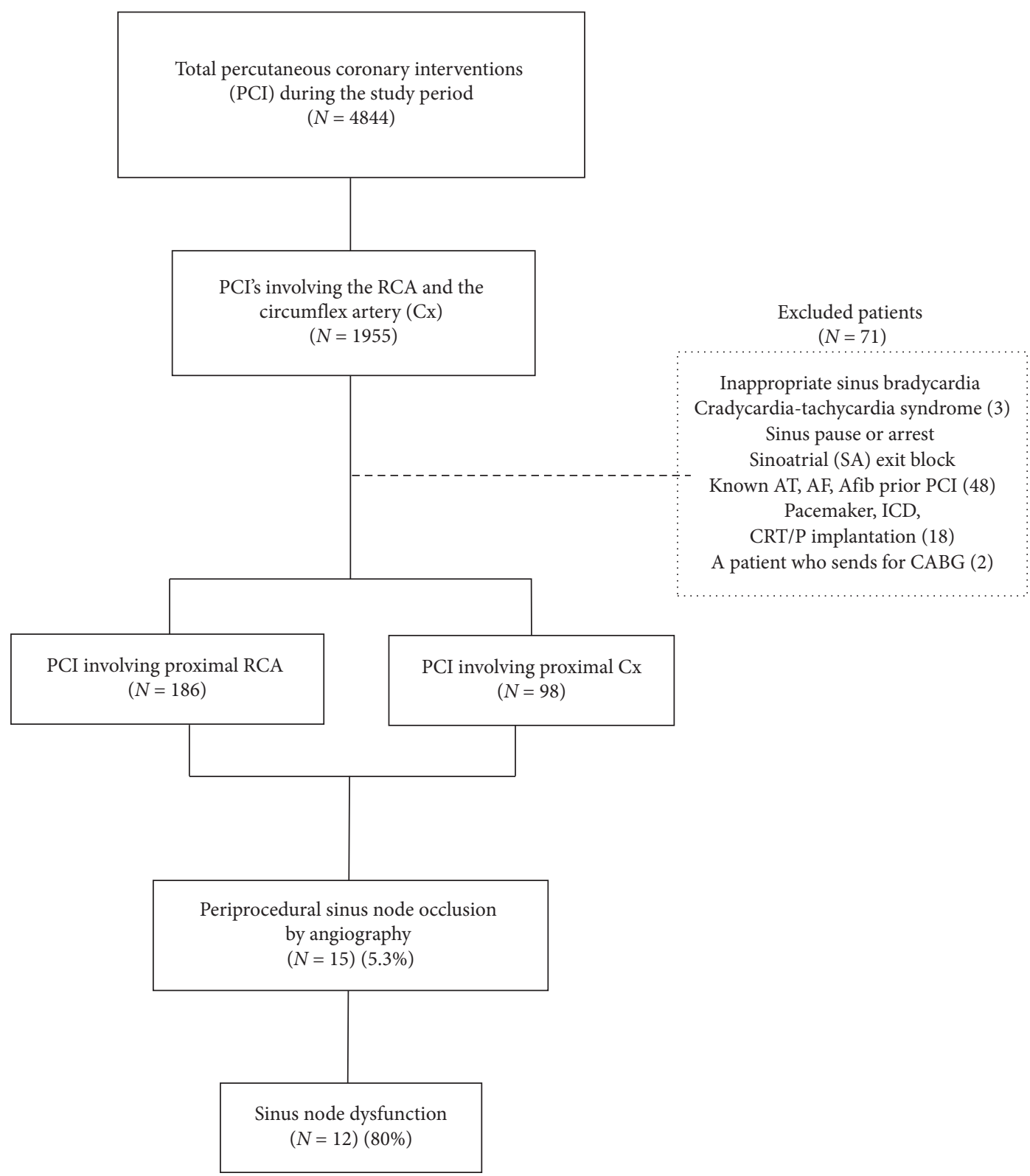

Figure 1: Study plan. AT, atrial tachycardia; AF, atrial flutter; AFib, atrial fibrillation; PCI, percutaneous coronary intervention.

cases were related to the phenomenon known as Bezold-Jarisch reflex $[16,17]$.

All cases of sinus bradycardia following SNO were transient with short duration and resolved uneventfully during the PCI. The appearance of junctional or escaped nodal rhythms following SNO may alert to a more severe and permanent arrhythmia, which will eventually require ventricular pacing. 


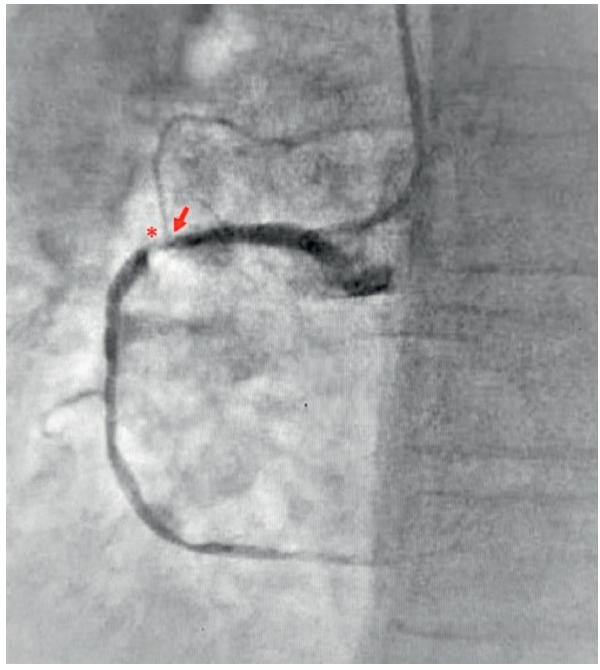

(a)

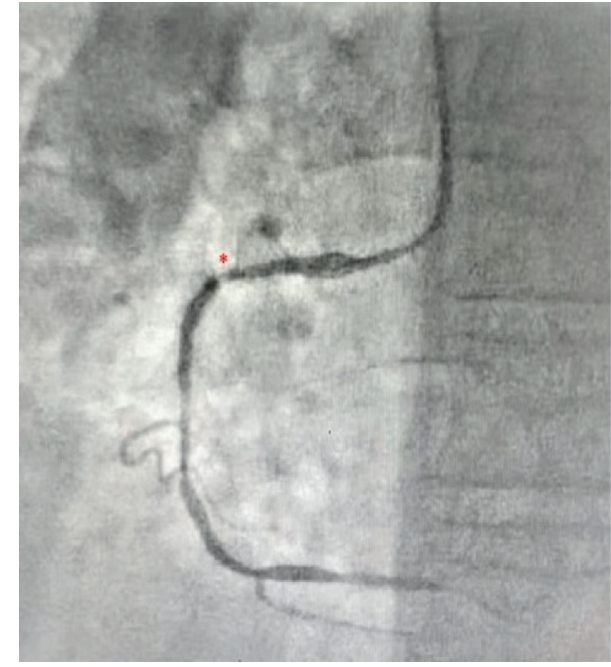

(b)

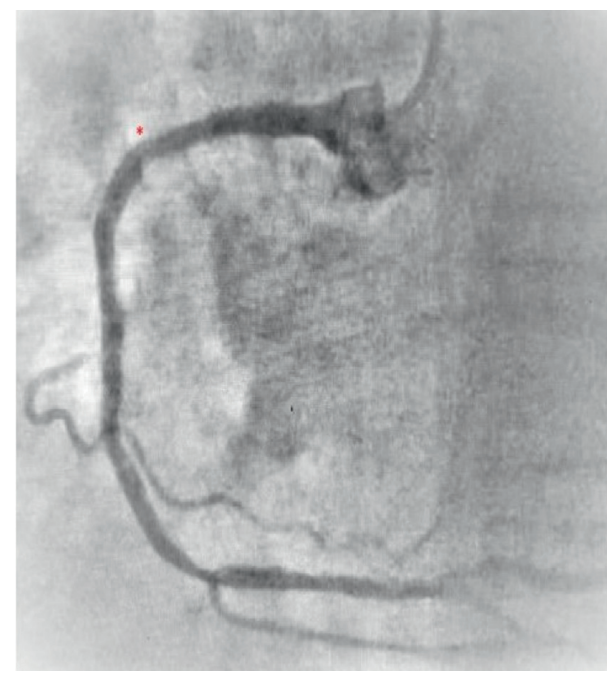

(c)

Figure 2: (a)-(c) Sinus node artery before and after PCI. (a) Right coronary angiography showing 95\% narrowing in the proximal segment (red asterisk). Note the sinus node artery (SNA) originated from the proximal segment (red arrow). (b) RCA following ballooning. (c) Proximal segment stenting. Note the angiographic disappearance of the SNA (red asterisk).

Out of all SNO events, one patient developed SND, which resulted in hemodynamic instability and required permanent pacemaker implantation. PM interrogation reveals that the sinus node function has the potential to recover in several months.

All SNO has assessed angiography without intracoronary imaging, such as intravascular ultrasound (IVUS) or optical coherence tomography (OCT). We did not use any thrombotic aspiration technique during the PCIs. Therefore, we cannot firmly conclude a relationship between the thrombotic plaque or PCI technique and the appearance of SNO. Moreover, we did not find a statistically significant correlation between stent's length, stent diameter, the formation of thrombus containing lesions, the need for pre- and postballoon dilatation, or TIMI flow due to the appearance of SND (Table 4 and Table 5).

To clearly understand the arrhythmogenic consequences of SNO, we excluded patients with baseline sinus bradycardia; therefore, the impact of nodal sinus dysfunction following SNO in this group remains unclear.

4.1. Limitation of the Study. The major limitation of the study is the methodology of the study. Our study is a cohort and retrospective, so we relied only on the quality and views already done. However, our interventional team is small, and there is no significant difference in the catheterization technique. Three senior cardiologists reviewed the cases separately in order not to influence the results. In case of disagreement, we consult all interventionalists.

Given the rarity of the outcome, which was significantly lower than expected, the small study group limits our ability to draw meaningful conclusions regarding risk factors but instead presents a snapshot of the phenomenon.

We collected data in a retrospective manner using Clalit Health Services' computer records, which may 
TABLE 2: Patient characteristics.

\begin{tabular}{lc}
\hline Patients characteristics & Number (\%) \\
\hline Age (years) & $69.58 \pm 8.85$ \\
Average \pm SD, range & $43-82$ \\
Male & $13(86)$ \\
Obesity & $6(40)$ \\
Smoker & $9(60)$ \\
Hyperlipidemia & $15(100)$ \\
Hypertension & $11(73)$ \\
Diabetes mellitus & $8(53)$ \\
PCI & $2(13)$ \\
Elective PCI & $4(27)$ \\
Urgent & $9(60)$ \\
Primary & \\
Presentation & $9(60)$ \\
STEMI & $4(27)$ \\
Non-STEMI & $15(100)$ \\
Artery involved & $0(0)$ \\
Right coronary artery & \\
Circumflex artery & \\
\hline
\end{tabular}

STEMI, ST-elevation myocardial infarction; NSTEMI, non-ST elevation myocardial infarction.

TABLE 3: Detailed information regarding sinus node dysfunction.

\begin{tabular}{|c|c|c|c|c|c|c|}
\hline & Age & Presentation & $\begin{array}{l}\text { SND appearance and } \\
\text { type }\end{array}$ & $\begin{array}{l}\text { Duration of } \\
\text { SND }\end{array}$ & Major complains & Clinical outcome \\
\hline 1 & 64 & NSTEMI & Nodal rhythm & $10 \mathrm{~min}$ & Presyncope & Resolved spontaneously \\
\hline 2 & 72 & NSTEMI & Sinus bradycardia & 2 minutes & Dizziness, general weakness & $\begin{array}{c}\text { Resolved } \\
\text { spontaneously } \mathrm{X}\end{array}$ \\
\hline 3 & 64 & STEMI & Nodal rhythm & 24 hours & Continuous dizziness, sweating & $\begin{array}{l}\text { Temporary PM } \\
\text { implantation }\end{array}$ \\
\hline 4 & 61 & STEMI & Nodal rhythm & $1-3$ months & $\begin{array}{l}\text { General weakness, reduced functional } \\
\text { capacity, effort dyspnea }\end{array}$ & $\begin{array}{l}\text { Permanent PM } \\
\text { implantation }\end{array}$ \\
\hline 5 & 69 & STEMI & Nodal rhythm & 3 hours & Headache, presyncope & $\begin{array}{l}\text { Temporary PM } \\
\text { implantation }\end{array}$ \\
\hline 6 & 70 & STEMI & None & & & \\
\hline 7 & 64 & STEMI & None & & & \\
\hline 8 & 65 & STEMI & Nodal rhythm & 3 hours & Shortness of breath, sweating & $\begin{array}{l}\text { Resolved with } \\
\text { medication }\end{array}$ \\
\hline 9 & 78 & Elective PCI & Sinus bradycardia & 4 minutes & Light-headedness & Resolved spontaneously \\
\hline 10 & 82 & Elective PCI & Nodal rhythm & 45 minutes & Presyncope, headache & $\begin{array}{c}\text { Resolved with } \\
\text { medication }^{\mathrm{Y}}\end{array}$ \\
\hline 11 & 75 & STEMI & Nodal rhythm & 6 hours & Headache, dizziness & $\begin{array}{l}\text { Resolved with } \\
\text { medication }\end{array}$ \\
\hline 12 & 43 & NSTEMI & None & & & \\
\hline 13 & 72 & STEMI & Nodal rhythm & 1.5 hours & Headache, sweating, weakness & $\begin{array}{c}\text { Resolved with } \\
\text { medication }\end{array}$ \\
\hline 14 & 52 & STEMI & Sinus bradycardia & 12 minutes & General weakness & Resolved spontaneously \\
\hline 15 & 81 & NSTEMI & Sinus bradycardia & 8 minutes & Dizziness & Resolved spontaneously \\
\hline
\end{tabular}

Resolved after vigorous cough; ${ }^{\mathrm{Y}}$ resolved after the use of $1 \mathrm{mg}$ adrenaline; ${ }^{\mathrm{Z}}$ resolved after the use of $1 \mathrm{mg}$ atropine. SND, sinus nodal dysfunction; PM, pacemaker; STEMI, ST-elevation myocardial infarction; NSTEMI, non-ST elevation myocardial infarction. 
TABle 4: Angiographic data of the study population.

\begin{tabular}{|c|c|c|c|c|c|c|c|c|c|c|}
\hline & Age & Presentation & SND & $\begin{array}{c}\text { Thrombus } \\
\text { containing } \\
\text { lesion }\end{array}$ & $\begin{array}{c}\text { Balloon } \\
\text { predilatation }\end{array}$ & $\begin{array}{c}\text { Balloon } \\
\text { postdilatation }\end{array}$ & $\begin{array}{l}\text { Stent }{ }^{¥} \\
\text { length }\end{array}$ & $\begin{array}{c}\text { Stent } \\
\text { diameter }\end{array}$ & $\begin{array}{l}\text { TIMI flow } \\
\text { prestenting }\end{array}$ & $\begin{array}{c}\text { TIMI flow } \\
\text { poststenting }\end{array}$ \\
\hline 1 & 64 & NSTEMI & $\begin{array}{l}\text { Nodal } \\
\text { rhythm }\end{array}$ & No & No & No & 12 & 2.0 & 1 & 3 \\
\hline 2 & 72 & NSTEMI & $\begin{array}{c}\text { Sinus } \\
\text { bradycardia }\end{array}$ & No & No & No & 16 & 2.0 & 1 & 3 \\
\hline 3 & 64 & STEMI & $\begin{array}{l}\text { Nodal } \\
\text { rhythm }\end{array}$ & Yes & Yes & Yes & 28 & 2.5 & 0 & 3 \\
\hline 4 & 61 & STEMI & $\begin{array}{l}\text { Nodal } \\
\text { rhythm }\end{array}$ & Yes & Yes & Yes & 22 & 3.0 & 0 & 3 \\
\hline 5 & 69 & STEMI & $\begin{array}{l}\text { Nodal } \\
\text { rhythm }\end{array}$ & No & Yes & Yes & 26 & 2.5 & 0 & 3 \\
\hline 6 & 70 & STEMI & None & No & No & No & 16 & 2.5 & 0 & 3 \\
\hline 7 & 64 & STEMI & None & No & No & No & 26 & 3.0 & 0 & 3 \\
\hline 8 & 65 & STEMI & $\begin{array}{l}\text { Nodal } \\
\text { rhythm }\end{array}$ & Yes & Yes & No & 14 & 3.5 & 0 & 3 \\
\hline 9 & 78 & Elective PCI & $\begin{array}{c}\text { Sinus } \\
\text { bradycardia }\end{array}$ & No & No & Yes & 16 & 2.5 & 2 & 3 \\
\hline 10 & 82 & Elective PCI & $\begin{array}{l}\text { Nodal } \\
\text { rhythm }\end{array}$ & No & No & No & 20 & 2.0 & 2 & 3 \\
\hline 11 & 75 & STEMI & $\begin{array}{l}\text { Nodal } \\
\text { rhythm }\end{array}$ & Yes & Yes & Yes & 12 & 2.5 & 0 & 3 \\
\hline 12 & 43 & NSTEMI & None & No & No & No & 14 & 2.5 & 0 & 3 \\
\hline 13 & 72 & STEMI & $\begin{array}{l}\text { Nodal } \\
\text { rhythm }\end{array}$ & No & No & No & 18 & 3.0 & 0 & 3 \\
\hline 14 & 52 & STEMI & $\begin{array}{c}\text { Sinus } \\
\text { bradycardia }\end{array}$ & No & Yes & Yes & 20 & 3.0 & 0 & 3 \\
\hline 15 & 81 & NSTEMI & $\begin{array}{c}\text { Sinus } \\
\text { bradycardia }\end{array}$ & No & No & No & 22 & 2.5 & 1 & 2 \\
\hline
\end{tabular}

${ }^{{ }^{*} T h i r d-g e n e r a t i o n ~ d r u g-e l u t i n g ~ s t e n t s ~ w e r e ~ u s e d ~ i n ~ a l l ~ p r o c e d u r e s . ~}$

TABLE 5: Multivariant analysis for SND outcome.

\begin{tabular}{|c|c|c|c|c|}
\hline & No SND, $N=3(\%)$ & $\mathrm{SND}, N=12(\%)$ & Total, $N=15(\%)$ & $P$ value \\
\hline Age & $59 \pm 14.17$ & $69.58 \pm 8.85$ & $67.47 \pm 10.46$ & 0.120 \\
\hline STEMI presentation & $2(66.7)$ & $7(58.3)$ & $9(60)$ & 0.744 \\
\hline Thrombus containing lesion & $0(0)$ & $4(33.3)$ & $4(26.7)$ & 0.243 \\
\hline Balloon predilatation & $0(0)$ & $6(50)$ & $6(40)$ & 0.114 \\
\hline Balloon postdilatation & $0(0)$ & $6(50)$ & $6(40)$ & 0.114 \\
\hline Stent length & $18.67 \pm 6.42$ & $18.83 \pm 5.14$ & $18.80 \pm 5.171$ & 0.711 \\
\hline Stent diameter & $2.67 \pm 0.28$ & $2.58 \pm 0.46$ & $2.6 \pm 0.43$ & 0.709 \\
\hline TIMI flow O prestenting & $3(100)$ & $7(58.3)$ & $10(66.7)$ & 0.392 \\
\hline TIMI flow III poststenting & $3(100)$ & $11(91.7)$ & $14(93.3)$ & 0.605 \\
\hline
\end{tabular}

underestimate long-term SND's true incidence. Clalit Health Fund is the largest of Israel's four health funds, with more than half of Israel's citizens' members. The HMO's computer system is continuously updating medical information from all medical services, including other health service organizations, and therefore, the risk of missing vital information is significantly low.

\section{Conclusion}

Following angioplasty of the RCA and circumflex arteries' proximal segments, sinus node artery occlusion is rare yet poses a significant risk for developing sinus node dysfunction. In most cases, the SND is uneventful and either resolved spontaneously or with medical treatment, usually within minutes. In only sporadic cases, persistent SND appears and requires the implantation of ventricular pacing. Long-term follow-up reveals that sinus node function in most persistent SND cases tends to recover, mostly within 24 hours from PCI.

Most of the cases of SNO occur during urgent PCI following acute coronary syndrome. We could not conclude or indicate risk factors related to patients' characteristics or PCI techniques and SNO or SND appearance.

\section{Data Availability}

The full data used to support the findings of this study are available from the corresponding author upon request. 


\section{Conflicts of Interest}

The authors declare that they have no conflicts of interest.

\section{Acknowledgments}

We would like to thank Dr. Polat Bangiyev and Dr. Regina Koren for their assistance and contribution to the study.

\section{References}

[1] M. K. Kyriakidis, C. B. Kourouklis, J. T. Papaioannou, S. G. Christakos, G. P. Spanos, and D. G. Avgoustakis, "Sinus node coronary arteries studied with angiography," The American Journal of Cardiology, vol. 51, pp. 749-750, 1983.

[2] F. Q. Almeda, S. Nathan, J. E. Calvin, J. E. Parrillo, and L. W. Klein, "Frequency of abrupt vessel closure and side branch occlusion after percutaneous coronary intervention in 6.5 years (1994 to 2000) at a single medical center," The American Journal of Cardiology, vol. 89, no. 10, pp. 1151-1155, 2002.

[3] M. Kotoku, A. Tamura, and S. Naono, "Sinus arrest caused by occlusion of sinus node artery during percutaneous coronary intervention for lesions of the proximal right coronary artery," Heart Vessels, vol. 22, pp. 389-392, 2007.

[4] J. Alvares-Garcia, M. Vives-Borras, A. Ferrero, D. A. Aizpurua, A. S. Penaranda, and J. Cinca, "Atrial coronary occlusion during selective percutaneous angioplasty," Cardiovascular Revascularization Medicine, vol. 14, pp. 270-274, 2013.

[5] P. Deeprasertkul and R. K. Thakur, "Sinus arrest following right coronary artery stent implantation," Archives of Internal Medicine, vol. 5, p. 11, 2012.

[6] E. S. Nakou, E. M. Simantirakis, E. I. Skalidis, and P. E. Vardas, "Long-standing sinus arrest due to the occlusion of the sinus node artery during the percutaneous coronary intervention: clinical implications and management," International Journal of Cardiology, vol. 203, pp. 432-433, 2016.

[7] Y. Abe, A. Tamura, and J. Kadota, "Prolonged sinus node dysfunction caused by obstruction of sinus node artery occurring during coronary stenting," Journal of Electrocardiology, vol. 41, pp. 656-658, 2008.

[8] D. Antonelli, E. Rozner, and Y. Turgeman, "Long-standing sinus arrest following the percutaneous coronary intervention of proximal right coronary artery," IMAJ, vol. 22, no. 3, pp. 197-198, 2020.

[9] J. Billette, V. Elharrar, G. Porlier, and R. A. Nadeau, "Sinus slowing produced by experimental ischemia of the sinus node in dogs," The American Journal of Cardiology, vol. 31, no. 3, pp. 331-335, 1973.

[10] R. Parameswaran, T. Ohe, and H. Goldberg, "Sinus node dysfunction in acute myocardial infarction," British Heart Journal, vol. 38, no. 1, pp. 93-96, 1976.

[11] M. Kyriakidis, A. Trikas, F. Triposkiadis et al., "Sinus node dysfunction in acute inferior myocardial infarction. Role of sinus node artery and clinical course in patients with onevessel coronary artery disease," Cardiology, vol. 88, no. 2, pp. 166-169, 1997.

[12] T. Haraki, H. Hirase, S. Hoda, M. Hashimoto, and M. Higashi, "Sinus dysfunction after stent implantation in the right coronary artery immediately recovered after reflow in the sinus node artery," Cardiovascular Intervention and Therapeutics, vol. 29, no. 2, pp. 173-176, 2014.

[13] D. Ahrensfield, C. W. Balke, R. M. Benitez, and R. W. Peters, "Transient sinus node dysfunction in acute myocardial infarction associated with the use of a coronary stent," Cardiovascular Intervention and Therapeutics, vol. 50, no. 3, pp. 349-351, 2000.

[14] E. Simonsen, B. L. Nielsen, and J. S. Nielsen, "Sinus node dysfunction in acute myocardial infarction," Acta Medica Scandinavica, vol. 208, no. 6, pp. 463-469, 1980.

[15] P. Alboni, G. F. Baggioni, S. Scarfò et al., "Role of sinus node artery disease in sick sinus syndrome in inferior wall acute myocardial infarction," The American Journal of Cardiology, vol. 67, no. 15, pp. 1180-1184, 1991.

[16] D. M. Aviado and D. Guevara Aviado, "The Bezold-Jarisch reflex. A historical perspective of cardiopulmonary reflexes," Annals of the New York Academy of Sciences, vol. 940, pp. 48-58, 2001.

[17] A. L. Mark, "The Bezold-Jarisch reflex revisited: clinical implications of inhibitory reflexes originating in the heart," Journal of the American College of Cardiology, vol. 1, no. 1, pp. 90-102, 1983. 